\title{
Research and mentorship as cornerstones of advancing academic emergency medicine globally
}

\author{
Latha G. Stead • Wyatt W. Decker
}

Received: 2 May 2008 / Accepted: 2 May 2008 / Published online: 12 June 2008

(C) Springer-Verlag London Ltd 2008

April 3rd marked the debut of the International Journal of Emergency Medicine's first issue and the first meeting of the Editorial Board. Several excellent ideas for advancing the mission of international emergency medicine arose. Of these, one recurrent theme was that of bringing to publication important work occurring in developing countries. While this is clearly one of the goals of the International Journal of Emergency Medicine, simply welcoming such contributions may not be adequate. Several barriers may preclude a manuscript from even being submitted, such as language barriers, inexperience with scientific writing or lack of guidance for how to develop a given manuscript. The importance of mentorship in a successful academic career has been documented [1].

With these concerns in mind, the Editorial Board of the International Journal of Emergency Medicine has decided to institute three new journal features:

1. An academic mentorship programme for authors wishing to contribute their work to the International Journal of Emergency Medicine

2. Standardized reporting guidelines for various study designs and

3. A new journal feature entitled "clinical research capsule".

L. G. Stead $(\bowtie) \cdot$ W. W. Decker

Generose G-410, Department of Emergency Medicine,

Mayo Clinic College of Medicine,

200 First Street SW,

Rochester, MN 55905, USA

e-mail: stead.latha@mayo.edu
The International Journal of Emergency Medicine academic mentorship programme is proposed to function as follows:

- Authors interested in the programme will fill out an electronic request that will be available on the website. The form will ask for information regarding the subject of the manuscript, the stage that it is in and the type of assistance required.

- Upon receipt of the form, the proposal will be evaluated. If accepted, a member of the Editorial Board will be assigned to the primary author, who will work with him or her to produce a high quality manuscript suitable for publication in the International Journal of Emergency Medicine.

Standardized reporting guidelines:

The International Journal of Emergency Medicine encourages reporting of research studies according to the following standardized guidelines referred to in the Uniform Requirements for Manuscripts Submitted to Biomedical Journals by the International Committee of Medical Journal Editors. These include:

- STROBE [2] (STrengthening the Reporting of OBservational studies in Epidemiology) statement—checklist of items that should be included in reports of cohort studies

- STARD [3] statement-checklist of items that should be included in reports of diagnostic studies

- MOOSE [4] statement-checklist of items that should be included in reports of meta-analyses 
- CONSORT [5] (Consolidated Standards of Reporting Trials) statement-checklist of items that should be included in reports of randomized clinical trials

\section{Clinical research capsule}

This new feature will succinctly cover a basic research topic in a format that can easily be adapted for use as a lecture. At the end of each calendar year, PowerPoint ${ }^{\circledR}$ slides of the material from each volume will be available for free download on the journal website. In order to make this information as accessible as possible to our international colleagues, we will print this feature in both English and Spanish. The proposed topics will be organized as follows:

Vol. 1 issue 2: Clinical research 101: why should you care? Vol. 1 issue 3: Understanding the statistical tests in the medical literature: which test should I use?

Vol. 1 issue 4: Designing research infrastructure

Vol. 2 issue 1: Study designs in clinical research part I: cohort, case-control and cross-sectional studies

Vol. 2 issue 2: Study designs in clinical research part II: systematic review and meta-analysis

Vol. 2 issue 3: Study designs in clinical research part III: clinical trials

Vol. 2 issue 4: Types of biases in clinical research
Clinical research is a vital component of medicine, both in moving the science of care forward, and in providing a unique aspect of contribution and career satisfaction for the academic emergency physician. Its integral relationship to the practice of emergency medicine makes it more than an interesting side note: it is a fundamental component of modern clinical practice.

\section{References}

1. Jackson VA, Palepu A, Szalacha L, Caswell C, Carr PL, Inui T (2003) "Having the right chemistry": a qualitative study of mentoring in academic medicine. Acad Med 78:328-334

2. Vandenbroucke JP, von Elm E, Altman DG, Gøtzsche PC, Mulrow CD et al (2007) Strengthening the Reporting of Observational Studies in Epidemiology (STROBE): explanation and elaboration. PLoS Med 4(10):e297

3. Bossuyt PM, Reitsma JB, Bruns DE, Gatsonis CA, Glasziou PP, Irwig LM, Moher D, Rennie D, de Vet HC, Lijmer JG (2003) Standards for reporting of diagnostic accuracy. The STARD statement for reporting studies of diagnostic accuracy: explanation and elaboration. Clin Chem 49(1):7-18

4. Stroup DF, Berlin JA, Morton SC, Olkin I, Williamson GD, Rennie D, Moher D, Becker BJ, Sipe TA, Thacker SB (2000) Meta-analysis of observational studies in epidemiology: a proposal for reporting. Meta-analysis Of Observational Studies in Epidemiology (MOOSE) group. JAMA 283(15):2008-2012

5. Moher D, Schulz KF, Altman DG (2001) The CONSORT statement: revised recommendations for improving the quality of reports of parallel-group randomised trials. Lancet 357(9263):1191-1194 